\title{
Cromakalim (BRL 34915) restores in vitro the membrane potential of depolarized human skeletal muscle fibres
}

\author{
A. Spuler ${ }^{1}$, F. Lehmann-Horn ${ }^{2}$, and P. Grafe ${ }^{1}$ \\ 1 Department of Physiology, University of Munich, Pettenkoferstrasse 12, D-8000 München 2, Federal Republic of Germany \\ 2 Department of Neurology, Technical University of Munich, Möhlstrasse 28, D-8000 München 80, Federal Republic of Germany
}

Summary. The purpose of the present study was to analyze the effects of cromakalim (BRL 34915), a potent drug from a new class of drugs characterized as " $\mathrm{K}^{+}$channel openers", on the electrical activity of human skeletal muscle. Therefore, intracellular recordings were used to measure the effects of cromakalim on the membrane potential and input conductance of fibres from human skeletal muscle biopsies. Cromakalim in a concentration above $1 \mu \mathrm{mol} / 1$ induced an increase in membrane $\mathrm{K}^{+}$conductance. This effect resulted in a membrane hyperpolarization. The magnitude of this polarization depended on the difference between resting and $\mathrm{K}^{+}$equilibrium potential. The effect had a rapid onset and was quickly reversible after washing. Fibres from two patients with hyperkalaemic periodic paralysis showed an excessive membrane depolarization during and also after exposure to an slightly elevated extracellular $\mathrm{K}^{+}$concentration. In the latter situation, cromakalim repolarized the fibres to the normal resting potential. Tolbutamide $(1 \mathrm{mmol} / \mathrm{l})$ and $\mathrm{Ba}^{2+}(3 \mathrm{mmol} / \mathrm{l})$ strongly antagonized the effect of cromakalim. The data show that cromakalim hyperpolarizes depolarized human skeletal muscle fibres maintained in vitro. The underlying mechanism is probably an activation of otherwise "silent", ATP-regulated $\mathrm{K}^{+}$channels. Such an effect may be of therapeutic benefit in a situation in which a membrane depolarization causes muscle paralysis.

Key words: Cromakalim $-\mathrm{K}^{+}$-channels - Tolbutamide Human skeletal muscle - Hyperkalaemic periodic paralysis

\section{Introduction}

A new class of drugs characterized as " $\mathrm{K}^{+}$channel openers" (Weston and Abbott 1987) has been described to influence the electrical and mechanical activity of a variety of smooth muscles (Hamilton et al. 1986; Weir and Weston 1986; Kreye et al. 1987; Quast 1987; Hollingsworth et al. 1987) and cardiac muscle (Escande et al. 1988; Osterrieder 1988). One potent drug from this group is cromakalim (BRL 34915). This compound also shows effects upon convulsive discharges in guinea pig hippocampal slices (Alzheimer and ten Bruggencate 1988). The present study was concerned with two experimental questions: (a) Does cromakalim influence electrophysiological parameters of human skeletal muscle? In particular, effects on diseased human muscle would be of interest and may lead to new therapeutic strategies. (b) How

Send offprint requests to A. Spuler at the above address does cromakalim activate the $\mathrm{K}^{+}$conductance of skeletal muscle? To answer these questions we performed electrophysiological recordings from human skeletal muscle biopsies maintained in vitro (Iaizzo and Lehmann-Horn 1988). The results of the present study show that cromakalim hyperpolarizes human skeletal muscle via an increase in membrane $\mathrm{K}^{+}$conductance. The effect on membrane potential can be seen more clearly when the potential deviates from the potassium equilibrium potential. Furthermore, the effect of cromakalim was blocked by tolbutamide. This may indicate that cromakalim activates otherwise "silent", ATPregulated $\mathrm{K}^{+}$channels (Sturgess et al. 1985; Stanfield 1987; Ashcroft 1988; Escande et al. 1988).

\section{Methods and Materials}

The experiments were performed on biopsies of human skeletal muscle (Iaizzo and Lehmann-Horn 1988). Fibre segments $(4-6 \mathrm{~cm}$ long) were removed from biceps brachii, deltoid, vastus medialis or vastus lateralis muscles under local anaesthesia. Such segments were obtained from: (1) patients who consented that a muscle biopsy be carried out for the in vitro diagnosis of susceptibility to malignant hyperthermia; (2) patients who require a muscle biopsy for clinical diagnosis; and (3) patients with a known neuromuscular disease who consented to have a muscle biopsy removed for experimental reasons only. All procedures were in accordance with the Ethics Committee of the Technische Universität München.

The preparations were transferred to a perspex chamber (volume $2 \mathrm{ml}$, flow rate $6.5 \mathrm{ml} / \mathrm{min}$ ) and superfused at $36^{\circ} \mathrm{C}$ with a solution (Bretag 1969) of the following composition (in $\mathrm{mmol} / \mathrm{l}$ ): $\mathrm{NaCl} 107.7 ; \mathrm{CaCl}_{2} 1.53 ; \mathrm{KCl} 3.48$; $\mathrm{MgSO}_{4} 0.69 ; \quad \mathrm{NaHCO}_{3} 26.2 ; \mathrm{NaH}_{2} \mathrm{PO}_{4} 1.67 ; \mathrm{Na}$-glucuronate 9.64 ; glucose 5.5 ; sucrose 7.6 (bubbled with $95 \%$ $\mathrm{O}_{2} / 5 \% \mathrm{CO}_{2} ; \mathrm{pH}$ 7.4). Most of the muscle fibres were impaled midway with two microelectrodes for recording of membrane potential and injection of current, respectively. Intracellular micro-electrodes were drawn on a DMZ universal puller (Zeitz Instrumente, Augsburg, FRG) and filled with $3 \mathrm{~mol} / 1 \mathrm{KCl}(5-10 \mathrm{M} \Omega$ ). An Axoclamp 2 (Axon Instruments, Burlingame, CA, USA) was used to inject current and to record membrane potential. Data were recorded and/ or stored on a digital oscilloscope (Nicolet 4094, Offenbach, FRG), a chart recorder ( $\mathrm{W}+\mathrm{W}$ recorder 316 ; Kontron, München, FRG), and a tape recorder (TEAC XR-310; nbn Elektronik, Herrsching, FRG).

Drugs were applied via the bathing solution. Tolbutamide was obtained from Sigma (München, FRG); 

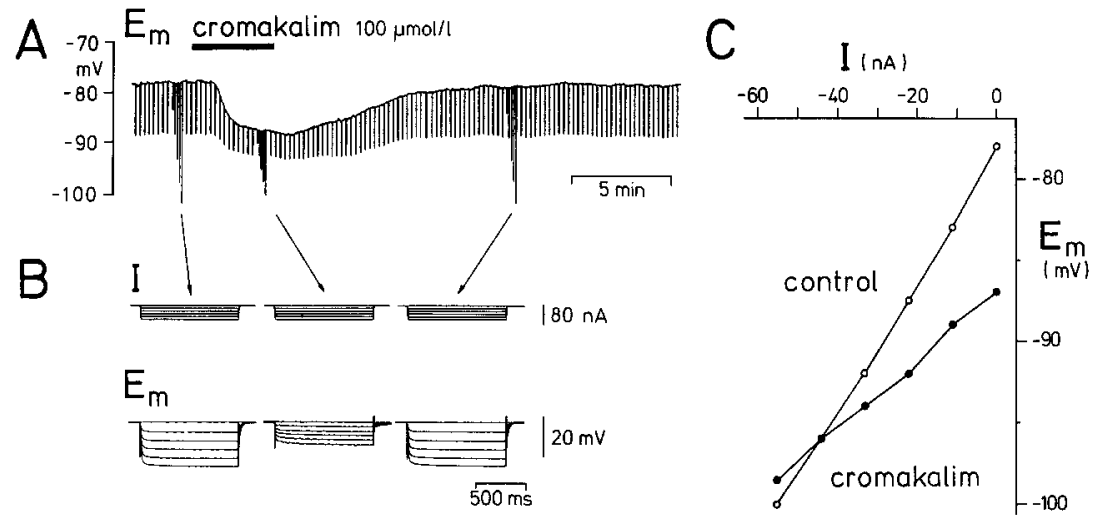

\begin{abstract}
Fig. 1A-C. Cromakalim enhances membrane $\mathrm{K}^{+}$conductance. Part A shows a continuous recording of membrane potential $\left(E_{\mathrm{m}}\right)$ and input resistance of a fibre from a skeletal muscle biopsy (no neuromuscular disease). Input resistance was determined every $15 \mathrm{~s}$ by hyperpolarizing current pulses $(40 \mathrm{nA}, 1 \mathrm{~s})$. B illustrates current-voltage relationships taken before, during and after the application of cromakalim. The $I-V$ curves before and during cromakalim are plotted in part $\mathbf{C}$. Note the reversal potential at $-95 \mathrm{mV}$
\end{abstract}

cromakalim (BRL 34915) was a gift from Beecham Pharmaceuticals (Gronau, FRG). Stock solutions $(100 \mathrm{mmol} / \mathrm{l}$ cromakalim, $1 \mathrm{~mol} / 1$ tolbutamide) were prepared in dimethyl sulfoxide (DMSO). DMSO did not mimic the effects of cromakalim or tolbutamide, respectively.

\section{Results}

Effects of cromakalim were explored on more than 60 fibres in skeletal muscle biopsies from 12 persons. The patients had the following diseases: myotonic dystrophy, chondrodystrophic myotonia (Schwartz-Jampel syndrome); hypokalaemic periodic paralysis $(2 \times$; see Fig. 3$)$, hyperkalaemic periodic paralysis $(2 \times$; see Fig. 5$)$, recessive generalized myotonia, amyotrophic lateral sclerosis (see Fig.2), myositis (see Fig. 4), and 3 persons without neurological diseases (these muscles were also tested for their susceptibility to malignant hyperthermia; see Fig 1). Resting membrane potentials in these fibres varied between -55 and $-85 \mathrm{mV}$. However, in spite of this wide range in resting potential, an uniform effect was seen when cromakalim was applied via the bathing solution. The effect consisted of a membrane hyperpolarization and an increase in membrane conductance. A typical example of the effects of cromakalim is illustrated in Fig. 1 (muscle biopsy was taken from a patient without muscle disease). The muscle fibre was impaled with two microelectrodes. One was used for the continuous recording of membrane potential; the other one served as current-delivering electrode. Hyperpolarizing current pulses $(40 \mathrm{nA}, 1 \mathrm{~s})$ were applied every $15 \mathrm{~s}$. Furthermore, current-voltage relationships were determined before, during, and after the action of cromakalim. Membrane currents itself were not recorded in the present study. The recording of this parameter would have needed the 3-microelectrode voltage clamp procedure (Adrian \& Marschall 1977) to account for the cable behaviour of the muscle biopsies, which had a length of $4-6 \mathrm{~cm}$. Therefore, all conclusions of the present study are based on changes in membrane potential and conductance.

Figure 1 shows that cromakalim produced a membrane hyperpolarization and an increase in membrane conductance. The current-voltage relationships revealed a reversal potential at $-95 \mathrm{mV}$ (see Fig. 1C). This indicates an increase in membrane $\mathrm{K}^{+}$conductance if one assumes no important alterations in the conductance of other channels during hyperpolarization from -78 to $-88 \mathrm{mV}$. This conclusion is further supported by the observation that cromakalim had similar effects when $\mathrm{Cl}^{-}$-free bathing solutions were used ( 4 observations, not illustrated). An increase in membrane $\mathrm{K}^{+}$conductance during cromakalim can also be deduced from the finding of an antagonistic effect of $\mathrm{Ba}^{2+}$ (see below).

The effect of cromakalim on the membrane potential $\left(E_{\mathrm{m}}\right)$ was dependent on the difference between resting - and $\mathrm{K}^{+}$equilibrium potential $\left(E_{\mathrm{K}}\right)$. Hyperpolarizations of up to $30 \mathrm{mV}$ were seen in fibres with resting potentials around $-55 \mathrm{mV}$. On the other hand, in fibres with resting potentials of $-85 \mathrm{mV}$, cromakalim had very little effect. Likewise, cromakalim did not hyperpolarize the depolarized membrane of fibres in a solution containing $20 \mathrm{mmol} / 1\left[\mathrm{~K}^{+}\right]_{\mathrm{e}}$. Changes in membrane potential in the normal bathing solution were used to determine the concentration-response behaviour of cromakalim. For the induction of a big difference between $E_{\mathrm{m}}$ and $E_{\mathrm{K}}$, blunt electrodes (tip diameter $1.5 \mu \mathrm{m}$ ) were used which produced an artificial, unspecific ion leak at the site of impalement. Figure 2 shows a typical example of such measurements; the observation was made on a muscle fibre from a patient with amyotrophic lateral sclerosis. The resting potential of this fibre was $-60 \mathrm{mV}$. Cromakalim was applied in concentrations between 10 and $100 \mu \mathrm{mol} / \mathrm{l}$. The drug induced a concentration-dependent membrane hyperpolarization. The effect had a rapid onset and was quickly reversible. Different concentrations of cromakalim were explored on another 22 fibres (application time 4-10 min). In all these recordings a minimal concentration of $3 \mu \mathrm{mol} / 1$ was necessary for a cromakalim-induced membrane hyperpolarization.

In a next series of experiments, the effects of the $\mathrm{K}^{+}$ channel blockers $\mathrm{Ba}^{2+}$ and tolbutamide on the action of cromakalim were explored. It was found that both, tolbutamide ( $1 \mathrm{mmol} / \mathrm{l})$ and $\mathrm{Ba}^{2+}(3 \mathrm{mmol} / \mathrm{l}$, not illustrated) strongly antagonized the effect of cromakalim. Figure 3 stems from a patient with hypokalaemic periodic paralysis. In normal bathing solution cromakalim produced a hyperpolarization of $20 \mathrm{mV}$; this effect was strongly reduced in the presence of $1 \mathrm{mmol} / \mathrm{l}$ tolbutamide. A lower concentration of tolbutamide $(0.3 \mathrm{mmol} / 1)$ was less effective. The interaction of tolbutamide with the effect of cromakalim was further analyzed by means of current-voltage relationships (see Fig. 4). These recordings revealed, in particular, that tolbutamide itself did not have an effect on the steady state membrane conductance in the range $\pm 25 \mathrm{mV}$ from the resting potential. Figure 4 illustrates five $I-V$ curves recorded consecutively from a single fibre (data stem from a patient with myositis). 
First (Fig. $4 \mathrm{~A}$ ), an $I-V$ curve in the presence of cromakalim $(100 \mu \mathrm{mol} / 1)$ was compared with one taken in normal bathing solution. This revealed an enhancement of membrane $\mathrm{K}^{+}$conductance (see also Fig. 1). Figure 4B shows $I-V$

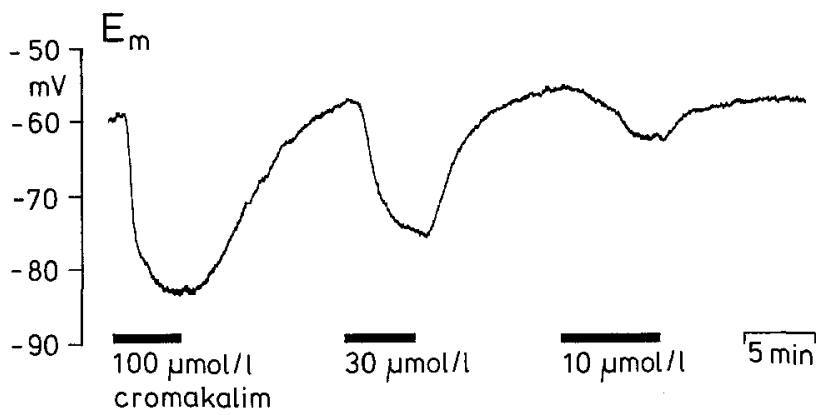

Fig. 2. Effects of cromakalim on membrane potential $\left(E_{\mathrm{m}}\right)$ of a human skeletal muscle biopsy (patient with amyotrophic lateral sclerosis). The resting potential of this fibre was $-60 \mathrm{mV}$. At this potential, concentration-dependent hyperpolarizations were induced by application of cromakalim to the bath

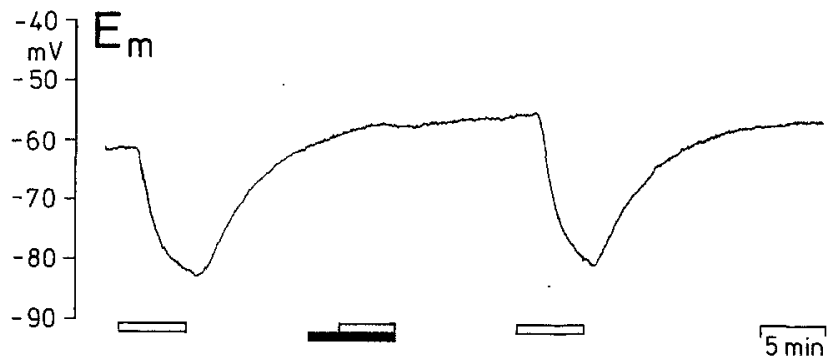

Fig. 3. Tolbutamide blocks the effect of cromakalim. The figure shows the recording of the membrane potential $\left(E_{\mathrm{m}}\right)$ of a fibre from a human skeletal muscle biopsy (patient with hypokalaemic periodic paralysis). Cromakalim $(100 \mu \mathrm{mol} / 1, \square)$ was applied first in the normal Bretag solution. It produced a hyperpolarization with a rapid onset. This effect was completely blocked in the presence of tolbutamide (1 $\mathrm{mmol} / \mathrm{l}$, curves taken $10 \mathrm{~min}$ after wash-out of cromakalim and $5 \mathrm{~min}$ after addition of tolbutamide $(1 \mathrm{mmol} / \mathrm{l})$ to the bathing solution. Tolbutamide did not show an effect of its own on the steady state membrane conductance. However, it strongly reduced the effect of cromakalim as shown in Fig. 4C. This plot shows $I-V$ curves in the presence of tolbutamide $(1 \mathrm{mmol} / 1)$ and when cromakalim $(100 \mu \mathrm{mol} / \mathrm{l})$ was added to a tolbutamide-containing bathing solution. Although most of the effect of cromakalim was blocked in this situation, there still was a tolbutamide-insensitive effect at less negative potentials.

The effect of cromakalim was explored on the depolarized state of fibres from two patients with hyperkalaemic periodic paralysis (h.p.p.). It has been previously described that h.p.p. muscle fibres respond with an activation of a non-inactivating $\mathrm{Na}^{+}$conductance when $\left[\mathrm{K}^{+}\right]_{\mathrm{e}}$ is slightly elevated (Lehmann-Horn et al. 1983, 1987a). As a consequence, the membrane depolarizes more than predicted by the Nernst equation for a given increase in $\left[\mathrm{K}^{+}\right]_{\mathrm{e}}$. Furthermore, $E_{\mathrm{m}}$ remains depolarized even when $\left[\mathrm{K}^{+}\right]_{\mathrm{e}}$ is lowered to the normal value. So far, in the in vitro experiments, only tetrodotoxin (TTX) was able to block this $\mathrm{Na}^{+}$ conductance and to repolarize the membrane (LehmannHorn et al. 1983, 1987a). We have now observed that a similar effect was induced by cromakalim. Figure 5 illustrates recordings of the membrane potential from h.p.p. muscle fibres. First, $\left[\mathrm{K}^{+}\right]_{\mathrm{e}}$ was elevated by $7 \mathrm{mmol} / 1$ (Fig. 5A). This resulted in a strong membrane depolarization and no repolarization was seen upon lowering $\left[\mathrm{K}^{+}\right]_{\mathrm{e}}$ to the normal resting level $(3.5 \mathrm{mmol} / \mathrm{l})$. However, the potential returned to the resting value soon after the addition of cromakalim $(100 \mu \mathrm{mol} / 1)$ to the normal bathing solution. Later on, the depolarized state was induced a second time; this time TTX was used to initiate a membrane repolarization. Figure 5B illustrates a recording of the potential from a different fibre. This time, $7 \mathrm{mmol} / 1 \mathrm{~K}^{+}$were added to the bathing solution in the presence of $100 \mu \mathrm{mol} / \mathrm{l}$ cromakalim; no abnormal behaviour was found. However, the same fibre came into a depolarized state when $7 \mathrm{mmol} / 1 \mathrm{~K}^{+}$were added
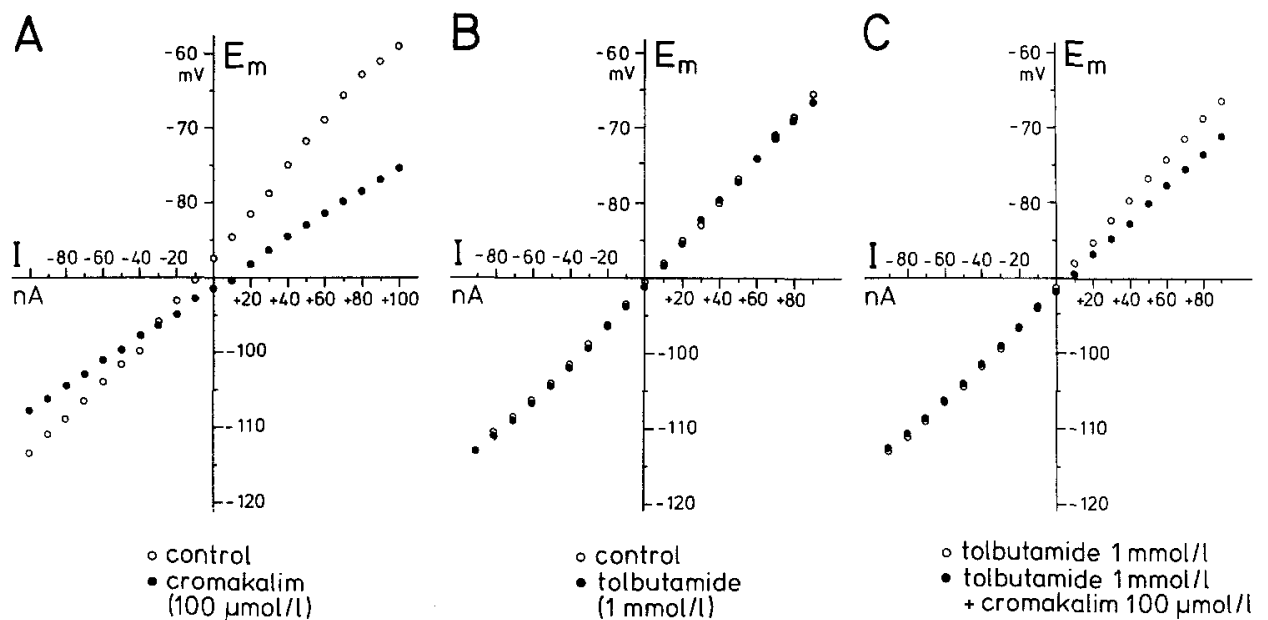

Fig. 4A-C. Effects of tolbutamide on the current-voltage (I-V) relationship of a human skeletal muscle fibre (patient with myositis). All $I-V$ curves were recorded consecutively from a single fibre (analysis was performed with potential values taken at the end of $1 \mathrm{~s}$ current pulses). A shows a comparison between $I-V$ curves taken in normal bathing solution and after cromakalim $(100 \mu \mathrm{mol} / 1)$ was added to this solution (application time $3 \mathrm{~min}$; a steady state effect was reached). B $I-V$ behaviour recorded 10 min after washing of cromakalim is compared with an $I-V$ curve in the presence of tolbutamide $(1 \mathrm{mmol} / 1$, application time $5 \mathrm{~min})$. C $I-V$ plots in the presence of tolbutamide and $3 \mathrm{~min}$ after cromakalim $(100 \mu \mathrm{mol} / 1)$ was added to the tolbutamide-containing solution are superimposed 

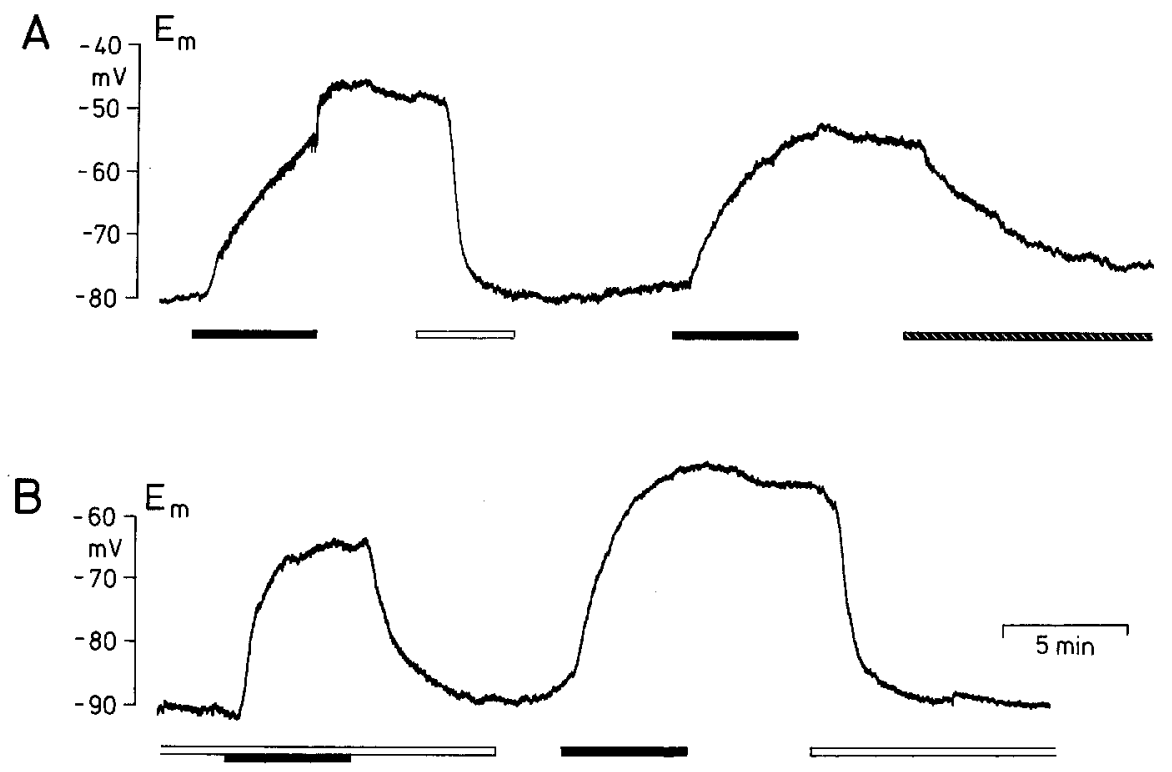

Fig. 5A, B. Cromakalim repolarizes the membrane in two different fibres from a patient with hyperkalaemic periodic paralysis (h.p.p.). A Addition of $7 \mathrm{mmol} / 1 \mathrm{~K}^{+}(\boldsymbol{E})$ to the normal bathing solution resulted in a depolarization of the membrane; the membrane remained in this depolarized state even after $\left[\mathrm{K}^{+}\right]_{\mathrm{e}}$ was lowered to its normal resting level $(3.5 \mathrm{mmol} / \mathrm{l}$; for further explanation see text). Cromakalim $(100 \mu \mathrm{mol} / \mathrm{l}, \square)$ restored the normal resting potential. Such a repolarization was also induced by tetrodotoxin (TTX, $0.6 \mu \mathrm{mol} / 1, \mathrm{~m}$ ). B When $7 \mathrm{mmol} / 1 \mathrm{~K}^{+}$were added in the presence of cromakalim no excessive membrane depolarization was seen. Later on, $7 \mathrm{mmol} / 1 \mathrm{~K}{ }^{+}$ were added to the normal bathing solution; this induced a membrane depolarization with the typical characteristics of a h.p.p. muscle fibre

to the normal bathing solution; cromakalim again was able to repolarize the membrane.

\section{Discussion}

The present study shows that cromakalim hyperpolarizes human skeletal muscle fibres. Such an effect deserves attention since it may be of therapeutic benefit in some kinds of skeletal muscle disease. For example, the hyperpolarizing effect of adrenaline on skeletal muscle has been shown to improve muscle strength in patients suffering from hyperkalaemic periodic paralysis (Wang and Clausen 1976; Bendheim et al. 1985): Cromakalim also hyperpolarizes smooth and cardiac muscle (for references see Introduction). In these preparations the action was explained by an increase in membrane $\mathrm{K}^{+}$conductance ( $\mathrm{gK}$ ). An enhancement of $\mathrm{gK}$ can also explain the effect on the membrane of skeletal muscle fibres. However, a hyperpolarization of more than $20 \mathrm{mV}$, which we have observed in some human muscle fibres, apparently seems to contradict such a view, since it is well known that the resting potential $\left(E_{\mathrm{m}}\right)$ in skeletal muscle is very close to the potassium equilibrium potential $\left(E_{\mathrm{K}}\right.$; Horowicz and Spalding 1986). Nevertheless, there is one experimental situation with a bigger difference between $E_{\mathrm{m}}$ and $E_{\mathrm{K}}$. The impalement itself creates a leak conductance with a reversal potential at $0 \mathrm{mM}$. The potential at the site of the impalement is, therefore, somewhere between the normal $E_{\mathrm{K}}$ and $0 \mathrm{mV}$. $E_{\mathrm{K}}$ itself does not change very much as a result of the electrode leak since the content of $\mathrm{K}^{+}$in large cells is very high. If $\mathrm{gK}$ increases near the site of impalement the leak conductance is short circuited and $E_{\mathrm{m}}$ shifts close to $E_{\mathrm{K}}$. Indeed, hyperpolarizations in the range of $20 \mathrm{mV}$ were only seen in fibres with a resting potential of around $-65 \mathrm{mV}$. However, some of the skeletal muscle biopsies had low membrane potentials even when electrodes with very fine tip diameters were used. In these situations an electrode leak seems unlikely to be the reason for the low membrane potential. Cromakalim was able to shift the potential of such fibres to around $-85 \mathrm{mV}$. This indicates that also such fibres had a rather normal intracellular $\mathrm{K}^{+}$ concentration. Therefore, we assume that an abnormally high $\mathrm{Na}^{+}$- or low $\mathrm{K}^{+}$conductance, respectively, may have caused the low resting potential. The reason for this change in the permeability ratio is unclear.

The next aspect concerns the type of $\mathrm{K}^{+}$channel activated by cromakalim. The blocking effect of $\mathrm{Ba}^{2+}$ is in accordance with the data of Osterrieder (1988). However, $\mathrm{Ba}^{2+}$ is a rather unspecific $\mathrm{K}^{+}$channel antagonist and this observation allows no conclusion which type of $\mathrm{K}^{+}$channel may be involved. Tolbutamide, on the other hand, has been reported to be a specific antagonist of ATP-regulated $\mathrm{K}^{+}$ channels in $\beta$ cells of rat islets of Langerhans (Sturgess et al. 1985). Tolbutamide did not have an effect of its own in our experiments. Nevertheless, it strongly antagonized the effect of cromakalim. Therefore, the following conclusion seems to be possible: Human skeletal muscle possess tolbutamide-sensitive, ATP-regulated $\mathrm{K}^{+}$channels which are closed under normal circumstances (Castle and Haylett 1987; Spruce et al. 1987; see also Belles et al. 1987 for data in cardiac muscle). Cromakalim is able to activate this conductance. The precise mechanism, however, of this interaction remains unclear. The same conclusion was drawn in a recent study about the effects of cromakalim on isolated cardiac myocytes (Escande et al. 1988). These authors showed that the effect of cromakalim was antagonized by low concentrations of glibenclamide, another specific blocker of ATP-dependent $\mathrm{K}^{+}$-channels.

Finally, the possible therapeutic use of cromakalim will be discussed. An exogenously-induced activation of $\mathrm{K}^{+}$conductance should have beneficial effects in human skeletal muscle diseases. Several muscle diseases have been described 
in which a membrane depolarization results in muscle paralysis (for review see Rüdel 1986). In paramyotonia (Lehmann-Horn et al. 1987b) and hyperkalaemic periodic paralysis (Lehmann-Horn et al. 1987a) the membrane depolarization was found to be due to an abnormal increase in $\mathrm{Na}^{+}$conductance. In hypokalaemic periodic paralysis, on the other hand, a decrease in gK may lead to a membrane depolarization (Gallant 1983). In all such situations an increase in $\mathrm{K}^{+}$conductance should help to repolarize the membrane and to improve muscle contraction force. In fact, cromakalim was able to repolarize in vitro depolarized fibres from a patient suffering from hyperkalaemic periodic paralysis (see Fig. 5). An enhancement of gK may be also beneficial in myotonic symptoms. However, the concentrations of cromakalim in our in vitro measurements were rather high ( $\mu \mathrm{mol} / 1$ range; see Fig. 2 ). It is possible that the higher susceptibility of vascular smooth muscle (nmol/1 range) prevents a therapeutic effect on skeletal muscle.

Acknowledgements. We would like to thank cand. med. S. Quasthoff for participation in some of the experiments, Ms. C. Müller for technical and secretarial assistance, Drs. M. Galvan and G. ten Bruggencate for helpful discussions, and Beecham Pharmaceuticals for the gift of cromakalim. This study was supported by the Wilhelm Sander Stiftung.

\section{References}

Adrian RH, Marshall MW (1977) Sodium currents in mammalian muscle. J Physiol (Lond) 268:223-250

Alzheimer C, ten Bruggencate G (1988) Actions of BRL 34915 (cromakalim) upon convulsive discharges in guinea pig hippocampal slices. Naunyn-Schmiedeberg's Arch Pharmacol $337: 429-434$

Ashcroft FM (1988) Adenosine 5'-triphosphate-sensitive potassium channels. Annu Rev Neurosci 11:97-118

Belles B, Hescheler J, Trube G (1987) Changes of membrane currents in cardiac cells induced by long whole-cell recordings and tolbutamide. Pflügers Arch 409:582-588

Bendheim PE, Reale EO, Berg BO (1985) $\beta$-Adrenergic treatment of hyperkalaemic periodic paralysis. Neurology 35:746-749

Bretag AG (1969) Synthetic interstitial fluid for isolated mammalian tissue. Life Sci 8:319-329

Castle NA, Haylett DG (1987) Effect of channel blockers on potassium efflux from metabolically exhausted frog skeletal muscle. J Physiol (Lond) 383:31 - 43

Escande D, Thuringer D, Leguern S, Cavero I (1988) The potassium channel opener cromakalim (BRL 34915) activates ATP-dependent $\mathrm{K}^{+}$channels in isolated cardiac myocytes. Biochem Biophys Res Commun 154:620-625

Gallant EM (1983) Barium-treated mammalian skeletal muscle: similarities to hypokalaemic periodic paralysis. J Physiol (Lond) 335:577-590
Hamilton TC, Weir SW, Weston AH (1986) Comparison of the effects of BRL 34915 and verapamil on electrical and mechanical activity in rat portal vein. Br J Pharmacol 88:103-111

Hollingsworth M, Amédée T, Edwards D, Mironneau J, Savineau JP, Small RC, Weston AH (1987) The relaxant action of BRL 34915 in rat uterus. Br J Pharmacol 91:803-813

Horowicz P, Spalding BC (1986) Electrical and ionic properties of the muscle cell membrane. In: Engel AG, Banker BO (eds) Myology. McGraw-Hill, New York, pp 445-470

Iaizzo PA, Lehmann-Horn F (1988) Long cut muscle fibers repolarize and possess electrical and mechanical properties of intact human skeletal muscle. Pflügers Arch 411:R191

Kreye VAW, Gerstheimer F, Weston AH (1987) Effects of the antihypertensive, BRL 34915, on membrane potential and ${ }^{86} \mathrm{Rb}$ efflux in rabbit tonic vascular smooth muscle. Pflügers Arch 408: R79

Lehmann-Horn F, Rüdel R, Ricker K, Lorkovic H, Dengler R, Hopf HC (1983) Two cases of adynamia episodica hereditaria: in vitro investigation of muscle cell membrane and contraction parameters. Muscle Nerve 6:113-121

Lehmann-Horn F, Küther G, Ricker K, Grafe P, Ballanyi K, Rüdel R (1987a) Adynamia episodia hereditaria with myotonia: a non-inactivating sodium current and the effect of extracellular pH. Muscle Nerve 10:363-374

Lehmann-Horn F, Rüdel R, Ricker K (1987b) Membrane defects in paramyotonia congenita (Eulenburg). Muscle Nerve 10:633641

Osterrieder W (1988) Modification of $\mathrm{K}^{+}$conductance of heart cell membrane by BRL 34915. Naunyn-Schmiedeberg's Arch Pharmacol 337:93-97

Quast U (1987) Effect of the $\mathrm{K}^{+}$efflux stimulating vasodilator BRL 34915 on ${ }^{86} \mathrm{Rb}^{+}$efflux and spontaneous activity in guineapig portal vein. Br J Pharmacol 91:569-578

Rüdel R (1986) The pathophysiological basis of the myotonias and the periodic paralyses. In: Engel AG, Banker BQ (eds) Myology. McGraw-Hill, New York, pp 1297-1311

Spruce AE, Standen NB, Stanfield PR (1987) Studies of the unitary properties of adenosine 5'-triphosphate-regulated potassium channels of frog skeletal muscle. J Physiol (Lond) 382:213236

Stanfield PR (1987) Nucleotides such as ATP may control the activity of ion channels. TINS 10:335-339

Sturgess NC, Ashford MLJ, Cook DL, Hales CN (1985) The sulphonylurea receptor may be an ATP-sensitive potassium channel. The Lancet II:474-475

Wang P, Clausen T (1976) Treatment of attacks in hyperkalaemic familial periodic paralysis by inhalation of salbutamol. The Lancet I : $221-223$

Weir SW, Weston AH (1986) The effects of BRL 34915 and nicorandil on electrical and mechanical activity and on ${ }^{86} \mathrm{Rb}$ efflux in rat blood vessels. Br J Pharmacol 88:121-128

Weston AH, Abbott A (1987) New class of antihypertensive acts by opening $\mathrm{K}^{+}$channels. TIPS $8: 283-284$

Received August 30, 1988/Accepted December 19, 1988 